\title{
LOS MUSEOS Y SU ROL COMO DIFUSORES DEL PASADO PREHISPÁNICO EN BOLIVIA: UN ESTADO DE LA CUESTIÓN
}

\author{
THE MUSEUMS AND THEIR ROLE AS TRANSMITTERS OF THE PREHISPANIC \\ PAST IN BOLIVIA: STATE OF THE ISSUE
}

\author{
Claudia Rivera Casanovas ${ }^{1}$
}

\begin{abstract}
Bolivia es un país con un rico y diverso pasado prehispánico. Las investigaciones arqueológicas realizadas en las últimas décadas, así como trabajos etnográficos y etnohistóricos, han ampliado en gran medida los conocimientos sobre las sociedades prehispánicas, sus trayectorias históricas regionales, sus formas de organización y de subsistencia, además de sus aspectos ideológicos y de cultura material. La información arqueológica sobre distintas regiones del país ha permitido construir secuencias y procesos que enriquecen en gran medida las historias locales y regionales. La difusión de este conocimiento debiera llegar a distintas audiencias de varias formas, siendo los museos espacios privilegiados para este propósito. Este trabajo está centrado en entender cómo la información arqueológica producida en ámbitos académicos y de investigación se incorpora dentro de las exposiciones y actividades en distintos museos nacionales, universitarios, municipales, regionales, comunitarios y otros. Al mismo tiempo, explora los probables grados de impacto y aceptación en el público general. En particular, se evalúa si los museos cumplen un rol significativo, contribuyendo a la formación de un imaginario colectivo sobre el pasado prehispánico a distintas escalas.
\end{abstract}

Palabras claves: museos, Bolivia, pasado prehispánico, arqueología, imaginario colectivo.

Bolivia is a country with a rich and diverse pre-Hispanic past. The archaeological investigations carried out in recent decades, as well as the ethnographic and ethnohistorical works, have greatly expanded the knowledge about pre-Hispanic societies, their regional historical trajectories, their forms of organization and subsistence, as well as their ideological and material culture aspects. The archaeological information on different regions of the country has allowed to build sequences and processes that greatly enrich local and regional histories to a large extent. The dissemination of this knowledge should reach different audiences in various ways, with museums being privileged spaces for this purpose. This work focuses on understanding how the archaeological information produced in the academic and research fields is incorporated into exhibitions and activities in different types of museums (national, university, municipal, regional, community and others). At the same time, it explores the probable degree of impact and acceptance in the general public. In particular, it evaluates if museums play a significant role, contributing to the formation of a collective imagination about the pre-Hispanic past at different scales.

Key words: Museums, Bolivia, pre-Hispanic past, archaeology, collective imagination.

\section{Miradas al Pasado Prehispánico: Raíces Comunes}

En Latinoamérica la necesidad de crear museos surge, durante el siglo XIX, del interés de los nacientes Estados nacionales por generar una historia común y mostrar la diversidad de las riquezas naturales y culturales que sus territorios abarcaban. No es raro entonces encontrar, sobre todo en la segunda mitad de este siglo, una proliferación de estas entidades en las capitales de distintos países. El impulso también estuvo dado por una necesidad de emular a los países hegemónicos europeos y sus prácticas, además de la creciente necesidad de crear símbolos nacionales que materializasen ciertos valores y percepciones de las élites sobre la cultura e historia dentro de contextos políticos y sociales particulares (Rattunde 2017:18). Así los museos buscaban generar una identidad nacional, fomentando sentimientos de arraigo de lo propio (De Carli 2003:3). Los museos se convirtieron en centros de una nueva historia, aquella que se iba construyendo según las visiones de país que comenzaban a articularse, afirmando ideales de nación y celebrando una nueva visión histórica.

Estos museos nacieron como recintos de carácter público, siendo repositorios de una diversidad de colecciones. Dado el espíritu de la época, la mayor parte de ellos exhibía una colección de objetos cuya

\footnotetext{
${ }^{1}$ Instituto de Investigaciones Antropológicas y Arqueológicas, Laboratorio de Tecnologías Aditivas, Universidad Mayor de San Andrés, La Paz, Bolivia. clauri68@yahoo.com
}

Recibido: enero 2018. Aceptado: diciembre 2018. 
procedencia y función no siempre era conocida. Además, predominaba una visión tradicional en la que el objetivo principal, hablando de arqueología, era organizar la información tal vez por culturas, mostrar lo distintivo.

En este contexto, el desarrollo de los museos en Bolivia puede remontarse a 1838 cuando se crea el primer Museo Público, que funcionó originalmente en el edificio de lo que hoy en día es el Teatro Municipal de la ciudad de La Paz. Dicho repositorio se conformó con colecciones geológicas, de flora y fauna, así como con objetos arqueológicos y etnográficos cedidos por José Manuel Indaburo, intelectual y Obispo de La Paz. En 1846 el museo fue reinaugurado por el Presidente José Ballivián quien donó sus colecciones, buscando un lugar adecuado para exponer los trofeos de guerra que obtuvo en la batalla de Ingavi, contra el ejército peruano (1841), mostrando las glorias de la joven nación y de él mismo, como hábil estratega (Nicolás y Quisbert 2014:110; Rattunde 2017:48). Este museo universal sufrió varias transformaciones y traslados hasta que, en 1922, fue establecido definitivamente en la que fuera la casa de Arthur Posnansky, dando lugar al Museo Nacional. En este lugar se expusieron colecciones arqueológicas y etnográficas como parte de un continuo cultural, distinto al de la sociedad moderna (Boero 1993). No fue sino hasta la segunda mitad del siglo XX que cambiaron los paradigmas sobre el pasado y el presente en un contexto de grandes transformaciones sociales marcadas por la Revolución Nacional de 1952. El Estado boliviano incentivó una nueva ideología nacional en la que el mestizaje fue una de sus banderas y en la que era fundamental conocer las raíces pasadas, sean prehispánicas, históricas o aún más contemporáneas, de una sociedad moderna que avanzaba hacia un futuro exitoso y de integración (Ponce Sanginés 1980). También dio un fuerte impulso a la conformación de museos especializados que mostrasen esas múltiples facetas de la sociedad boliviana. Es así que se crean el Museo Nacional de Arqueología, el Museo Nacional de Etnografía y Folklore y el Museo Nacional de Arte. En la década de 1970 estos museos pasan a formar parte del Instituto Boliviano de Cultura (1975) para integrarse en un proyecto cultural estatal de amplio alcance en el que la difusión era prioritaria en la búsqueda de una historia y cultura nacional compartida.

Sin embargo, en otras regiones de Bolivia fuera de la sede de gobierno, distintas trayectorias históricas se presentaron en la conformación de museos. Fueron principalmente los espacios universitarios los que dieron lugar a la formación de museos relacionados con el pasado prehispánico, con una óptica mucho más regional. De este modo, desde la década de 1940 se tiene la fundación del Museo Antropológico de la Universidad Real Mayor y Pontificia de San Francisco Xavier en Sucre, el
Museo Arqueológico y Etnográfico de la Universidad Mayor de San Simón en Cochabamba (1951), el Museo Paleontológico y Arqueológico de la Universidad Juan Misael Saracho en Tarija (1959) y, más recientemente, el Museo de Historia de la Universidad Gabriel René Moreno en Santa Cruz y el Museo Universitario de la Universidad Tomás Frías de Potosí.

Los museos regionales relacionados con el tema arqueológico se fueron creando a partir de la década de 1970, en muchos casos bajo la dirección del Instituto Nacional de Arqueología, y presentan historias regionales bastante localizadas. Son casos comolos del Museo Regional de Tiwanaku, el Museo de Kusijata en Copacabana, el Museo de Iskanwaya y el Museo de Samaipata, entre algunos otros. Se debe destacar también la creación de museos municipales en varias regiones del país. Entre ellos están los museos municipales de La Paz, el Museo Antropológico Eduardo López Rivas en Oruro, el ya desaparecido Museo Municipal en Potosí y los museos de San Carlos, Saipina y Vallegrande en el departamento de Santa Cruz. Está también el Museo Kenneth Lee en Trinidad que depende de la Gobernación del departamento. En las dos últimas décadas se han ido estableciendo diversos museos comunitarios en varias regiones de Bolivia, muchos de ellos en función al desarrollo del turismo en sus regiones, y otros como parte final de proyectos arqueológicos efectuados en distintas localidades.

A partir de una mirada a estos repositorios surgen preguntas como: ¿existen parámetros comunes en estos repositorios para la exposición de materiales arqueológicos y la presentación de las sociedades pasadas al público?, ¿qué tipos de mensajes reciben los visitantes en estos lugares?, ¿se está generando un imaginario colectivo a partir de las exposiciones? Con estas interrogantes presento los datos correspondientes a las distintas categorías de museos analizados para este trabajo.

\section{Museos Nacionales}

Este tipo de museos se emplazan en las principales ciudades de Bolivia, siendo los más importantes en términos de categoría y también como difusores de las visiones históricas desde el Estado para la conformación de una comunidad nacional imaginada (ver Rattunde 2017, para una mayor discusión) (Figura 1). En general, son los más antiguos, contando con mayores recursos y posibilidades de llegada a un público amplio y variado.

\section{Museo Nacional de Arqueología (MUNARQ)}

Esta institución, que alberga una de las mayores colecciones arqueológicas en el país, fue creada en 1838 bajo la presidencia de Andrés de Santa Cruz y se abrió como Museo Público en 1846, albergando no solamente 


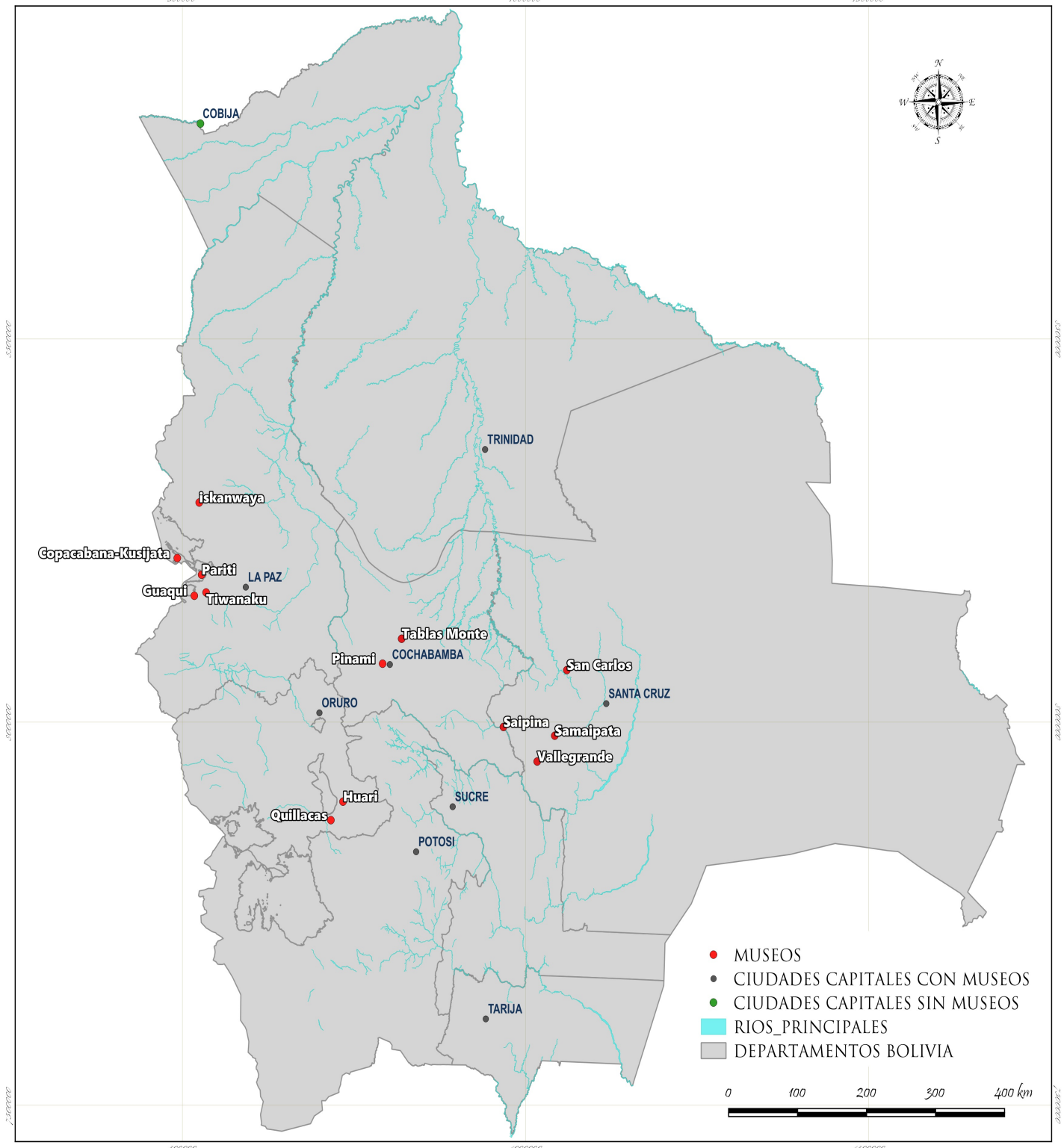

Figura 1. Mapa con la localización de lugares y museos mencionados en el texto.

Location map of places and museums mentioned in the text.

colecciones arqueológicas, sino un variado grupo de objetos etnográficos, naturales y otros. En 1922 pasó a funcionar como Museo Nacional Tiwanaku y a partir de 1960 se especializó en arqueología, formando el Museo Nacional de Arqueología de Bolivia (Boero 1993). Desde la década de 1920 este museo buscó realzar la importancia de Tiwanaku para el Estado boliviano como un referente prehispánico de civilización, útil en la búsqueda de los orígenes de la nación (Rattunde 2017).
Sus colecciones están conformadas por piezas provenientes de la colección de monseñor José Manuel Indaburo, así como la del coronel Federico Diez de Medina, además de muchas otras. Debido a su carácter nacional, en sus cinco salas las exposiciones se enfocan en transmitir al visitante un panorama general sobre la arqueología de Bolivia, la cronología de las culturas prehispánicas y sus características más relevantes. Como señalara Ponce Sanginés (1980:133), este museo fue concebido para mostrar visualmente los elementos 
de las antiguas culturas indígenas y lograr un entronque con el presente y las instituciones encargadas del patrimonio.

En este museo la forma de exposición se ha mantenido los últimos 40 años con cambios menores (básicamente en las vitrinas), priorizando mostrar piezas aisladas o en conjunto. En 2013, luego de una larga intervención administrativa, se trabajó en una "nueva museografía" para las exposiciones que incluía un cambio en el color de los muros y una nueva forma para presentar las colecciones. Se acudió a especialistas que proporcionaron insumos para un guion museográfico actualizado y para montar las exposiciones. Sin embargo, este trabajo se utilizó solo parcialmente por temas económicos y la presentación de la exposición se cambió en la medida de lo posible. Al realizar el recorrido por las salas se observa una disposición de los objetos seleccionados por materiales, líticos y cerámica principalmente, aunque en algunas vitrinas se presentan asociaciones entre materiales. Así, se avanza desde el periodo Arcaico hacia delante, a través de objetos que muestran sus características tecnológicas y estilísticas, siendo la cerámica el material privilegiado en todas las salas. Las vitrinas están acompañadas por paneles con textos explicativos que suelen ser largos, o por recuadros pequeños que contemplan información más puntual, por ejemplo, sobre talla de artefactos líticos. Para dar una idea sobre la geografía en la que se desarrollaron las culturas en exposición se han incorporado grandes fotografías que muestran paisajes de altiplano y valles. El altiplano boliviano es lo que más se prioriza con sus desarrollos culturales, siendo Tiwanaku el más importante al contar con toda una sala (Figura $2 \mathrm{a}$ y b). Los valles y tierras bajas los menos explicados y representados y el recorrido finaliza con el dominio inca en Bolivia. Información reciente sobre las distintas regiones se ha ido incorporando en los paneles explicativos. La exhibición del museo debería representar el pasado prehispánico del país en toda su extensión, sin embargo, es evidente que el énfasis de todo el conjunto está focalizado en la cuenca del lago Titicaca y particularmente en Tiwanaku, símbolo del Estado moderno.

El MUNARQ es el principal museo arqueológico en Bolivia, sin embargo, se mantiene tradicional en su forma de presentar la información, no cuenta con programas de investigación sostenidos y no existen actividades específicas para la comunidad ni los niños, aunque recientemente ofrece pasantías para estudiantes de arqueología que colaboren en labores de catalogación, conservación e investigación.

\section{Museo Nacional de Etnografía y Folklore (MUSEF)}

El MUSEF fue creado en 1962 por Julia Elena Fortún, profesional multifacética, como Museo de
Artesanía y Arte Popular en la casona colonial de los Marqueses de Villaverde. Con el tiempo fue adquiriendo y recibiendo importantes colecciones arqueológicas de todo el país, convirtiéndose en 1974 en el Museo Nacional de Etnografía y Folklore. Desde 1983 está bajo la tutela de la Fundación Cultural del Banco Central de Bolivia, habiéndoselo declarado como institución científica, educativa y cultural de interés nacional. En los últimos 15 años fue incorporando dentro sus investigaciones el componente arqueológico, que no puede desligarse del etnográfico si se quieren entender continuidades y cambios en las prácticas materiales y simbólicas a través del tiempo (ver Villanueva 2019, en este número). De manera diferente al MUNARQ, este museo creó espacios para el trabajo arqueológico y, a través de su Reunión Anual de Etnología (RAE), con casi 30 años de continuidad, siempre propició el debate y publicación de investigaciones arqueológicas. Ha apoyado también la investigación sobre arte rupestre que incorpora equipos multidisciplinarios. Sus salas de tejidos y cerámica sirvieron a la formación de estudiantes de arqueología por muchos años para hacer prácticas y diferenciar aspectos técnicos, funcionales y estilísticos de los materiales y sus filiaciones culturales. Es un museo con vínculos académicos, de investigación, programas diversos de exposición y programas para niños. Sus últimas publicaciones sobre catálogos de colecciones e investigación incorporan el componente arqueológico como básico a todas ellas. Cuenta con salas nuevas enfocadas en cadenas operativas y sus exposiciones se renuevan de manera constante, constituyéndose en un museo dinámico a nivel nacional.

\section{Museo Nacional de Arte (MNA)}

Este museo, creado en la década de 1970, también es parte de la Fundación Cultural del Banco Central de Bolivia desde 1983. Originalmente su enfoque estuvo dirigido al arte colonial y contemporáneo, habiendo incorporado recientemente (2011) una sección arqueológica en su primera sala con la que inicia el recorrido enfocado en el arte en Bolivia a lo largo de su historia (Figura 3). Nuevamente vemos la tendencia a presentar vitrinas con objetos líticos y cerámicos, además de algunos textiles de la costa, que pretenden dar una idea de cómo se desarrolló el arte a través del tiempo. Las piezas tienen pequeños textos que señalan la cultura y la cronología. También se han incorporado pantallas con videos que, en la siguiente sección, tocan temas antropológicos sobre sincretismo cultural durante el periodo Colonial y cómo las divinidades prehispánicas se mezclan con las cristianas, dando lugar a una religiosidad andina popular que integra los antiguos paisajes sagrados y los seres que los conforman. Este museo no proporciona mayor información sobre las piezas y recién está en proceso de desarrollar programas 

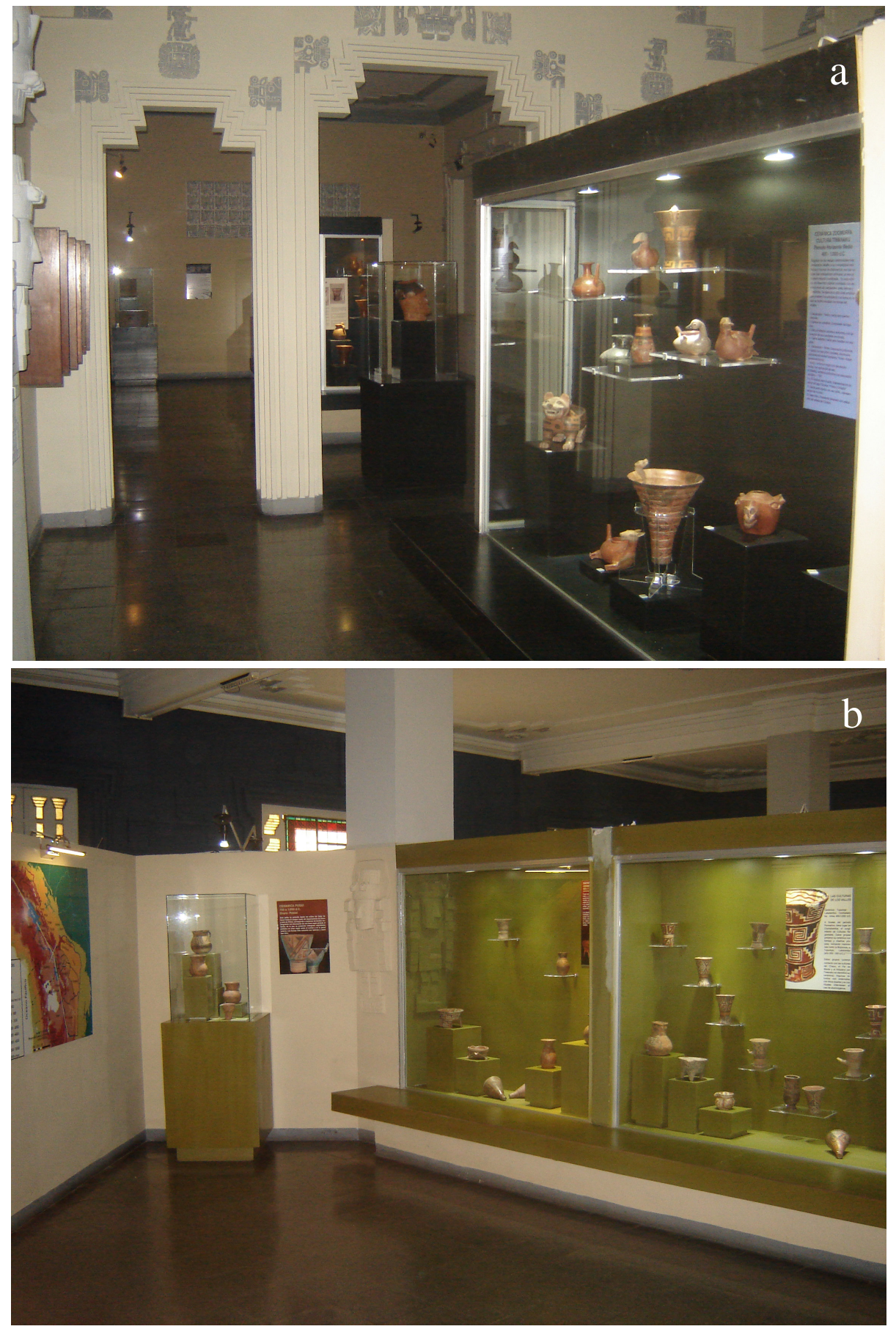

Figura 2. (a) Sala Tiwanaku, MUNARQ, La Paz. (b) Exposición cerámica de los valles de Bolivia, MUNARQ, La Paz. (a) Tiwanaku exhibition room, MUNARQ, La Paz. (b) Ceramic exhibition from the Bolivian valleys, MUNARQ, La Paz 
específicos con niños y la comunidad, aunque realiza distintos tipos de exposiciones temporales.

\section{Museos Universitarios}

Los museos universitarios surgen a partir de la década de 1940 principalmente en el sur y centro de Bolivia, siendo la arqueología uno de los componentes centrales dentro de sus exposiciones y actividades. Personalidades como Geraldine Byrne de Caballero, Dick Ibarra Grasso y Leonardo Branisa tuvieron un rol destacado en su conformación, sobresaliendo los museos en Sucre y Cochabamba. Más tardíamente se conforman los museos en Tarija, Santa Cruz y Potosí. Un elemento principal son sus actividades de investigación arqueológica, ya sea a cargo de sus miembros o a través de proyectos con instituciones nacionales y extranjeras.

\section{Instituto de Investigaciones Antropológicas y Museo Arqueológico de la Universidad Mayor de San Simón (INIAM)}

Este museo forma parte del Instituto de Investigaciones Antropológicas de dicha casa de estudios. Fue fundado en 1951 como Museo Arqueológico y Etnográfico de la Universidad Mayor de San Simón, siendo su primer director el arqueólogo argentino Dick Ibarra Grasso. En
1979 se convierte en el INIAM y, desde su fundación, ha realizado innumerables proyectos de investigación dentro del departamento de Cochabamba y en otras regiones, principalmente de valles y tierras bajas. Producto de estas investigaciones y la vasta actividad de Dick Ibarra Grasso, Geraldine Byrne y varios otros especialistas son buena parte de los objetos arqueológicos y etnográficos que hoy se exponen en sus salas (INIAM 2001). En estos espacios, organizados en torno a un recibidor central, las vitrinas presentan las culturas prehispánicas con un enfoque regional, principalmente del departamento de Cochabamba, desde los cazadores recolectores hasta la colonia (Figura 4). Posee también una sección etnográfica importante en la que resalta la colección de sistemas ideográficos de rezos en cuero y arcilla, usados en varias partes de Bolivia desde el periodo Colonial. Como en otros museos, se presentan objetos de cerámica y líticos, con una sala en la que están en una parte los textiles y en otra las momias y objetos de metal. En las exposiciones se puede apreciar la diversidad estilística y cronológica de los materiales expuestos.

El museo es prolífico en la producción de libros, revistas, catálogos de exposición y folletos, mediante los que difunde las investigaciones que realiza la institución, llegando a un público variado. Además, tiene toda esta información disponible en su página web para consulta y descarga. Entre sus actividades destacan los proyectos de investigación paleontológicos, arqueológicos y

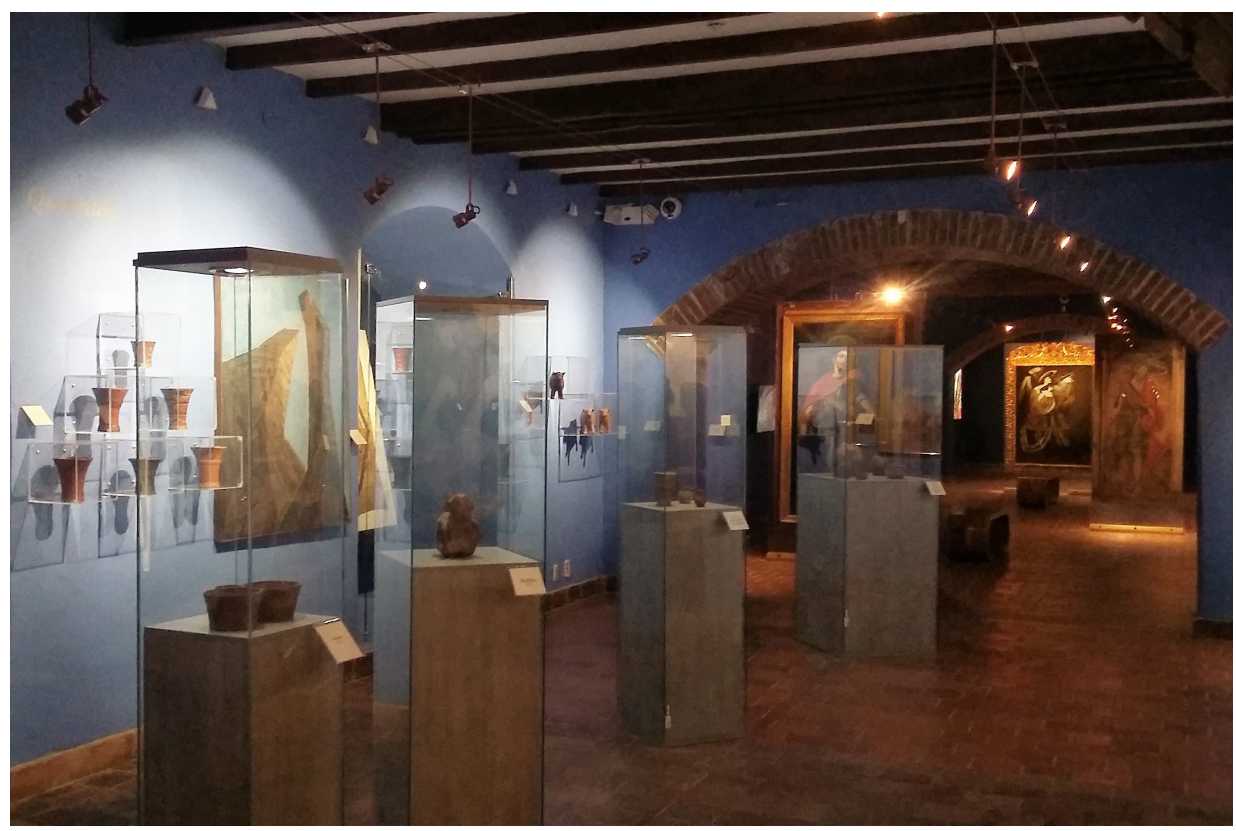

Figura 3. Sala Introductoria, MNA, La Paz Introductory exhibition room, MNA, La Paz. 


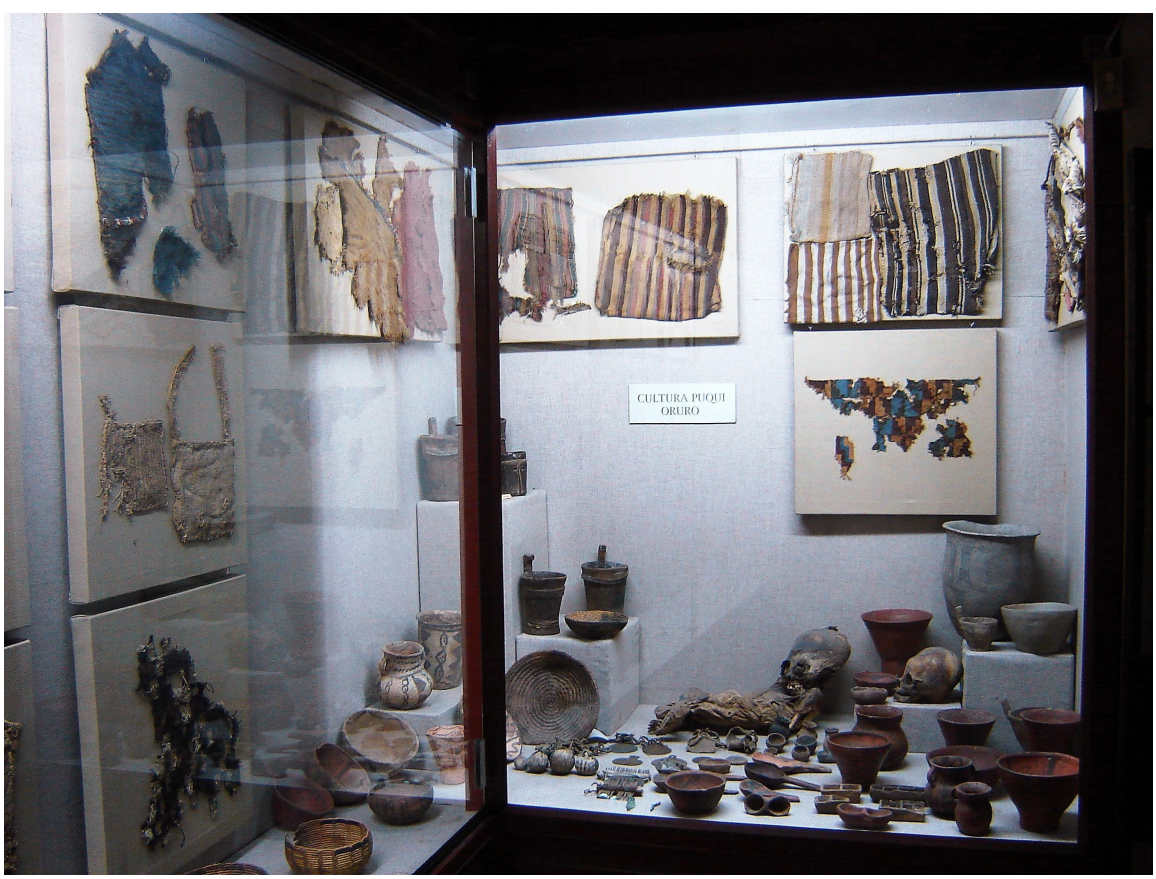

Figura 4. Sala de exposición INIAM, Cochabamba.

Exhibition room INIAM, Cochabamba.

etnográficos, así como proyectos internacionales mediante convenios de cooperación. A esto se suman acciones de gestión patrimonial con un registro y catálogo de sitios arqueológicos en el departamento de Cochabamba y acciones coordinadas con las comunidades y municipios.

En este caso, el museo sí cuenta con programas específicos para niños con un salón en el que pueden jugar excavando contextos arqueológicos para entender el principio de estratigrafía y los hallazgos bajo el suelo, además de hacer otras actividades. También tiene un guía especializado que los conduce por las salas realizando las explicaciones, según el caso, en español o quechua. Hay un espacio importante para los niños de áreas rurales que visitan el museo con sus colegios, los cuales reciben las explicaciones en su idioma nativo y en términos que les son familiares (Figura 5).

\section{Museo Antropológico de la Universidad Mayor de San Francisco Xavier}

En Sucre se encuentra el Museo Antropológico de la Universidad Real Mayor y Pontificia de San Francisco Xavier, creado en 1944 bajo del impulso de Geraldine Byrne de Caballero y otras personalidades locales, contando con más de 70 años. Es un museo importante por sus colecciones de referencia para la arqueología de los valles de Chuquisaca. Como en otros casos y con una visión regional, en las salas de exposición tienen prioridad las piezas cerámicas decoradas que están en vitrinas, acompañadas de pequeños carteles con la cronología y mapas que muestran la distribución regional de estos estilos (Figura 6). Forman también parte de la exposición, tejidos, instrumentos diversos, así como momias provenientes de varias cuevas funerarias de los valles de Chuquisaca. En una de las salas se reprodujo una cueva con arte rupestre, Inkamachay, para que el visitante tenga una experiencia interactiva. Aunque el museo realiza proyectos de investigación sostenidos y transmite estos trabajos mediante publicaciones de difusión general, no cuenta con programas específicos de interacción con la comunidad ni con los niños. Existen ciclos de charlas sobre arqueología y turismo.

\section{Otros museos universitarios}

En la ciudad de Tarija, el Museo Nacional Paleontológico, Mineralógico y Arqueológico de la Universidad Juan Misael Saracho es el más importante. Inició actividades en 1959 como Museo Paleontológico dependiente del municipio para luego ser transferido a la universidad (Amado 2013). A parte de una significativa colección paleontológica del Cuaternario y otra de mineralogía, cuenta con una amplia sala de arqueología en la que se exponen piezas cerámicas y otras de todo el departamento, mostrando su carácter regional. Los objetos tienen lugar de procedencia pero no se explica en mayor detalle su 


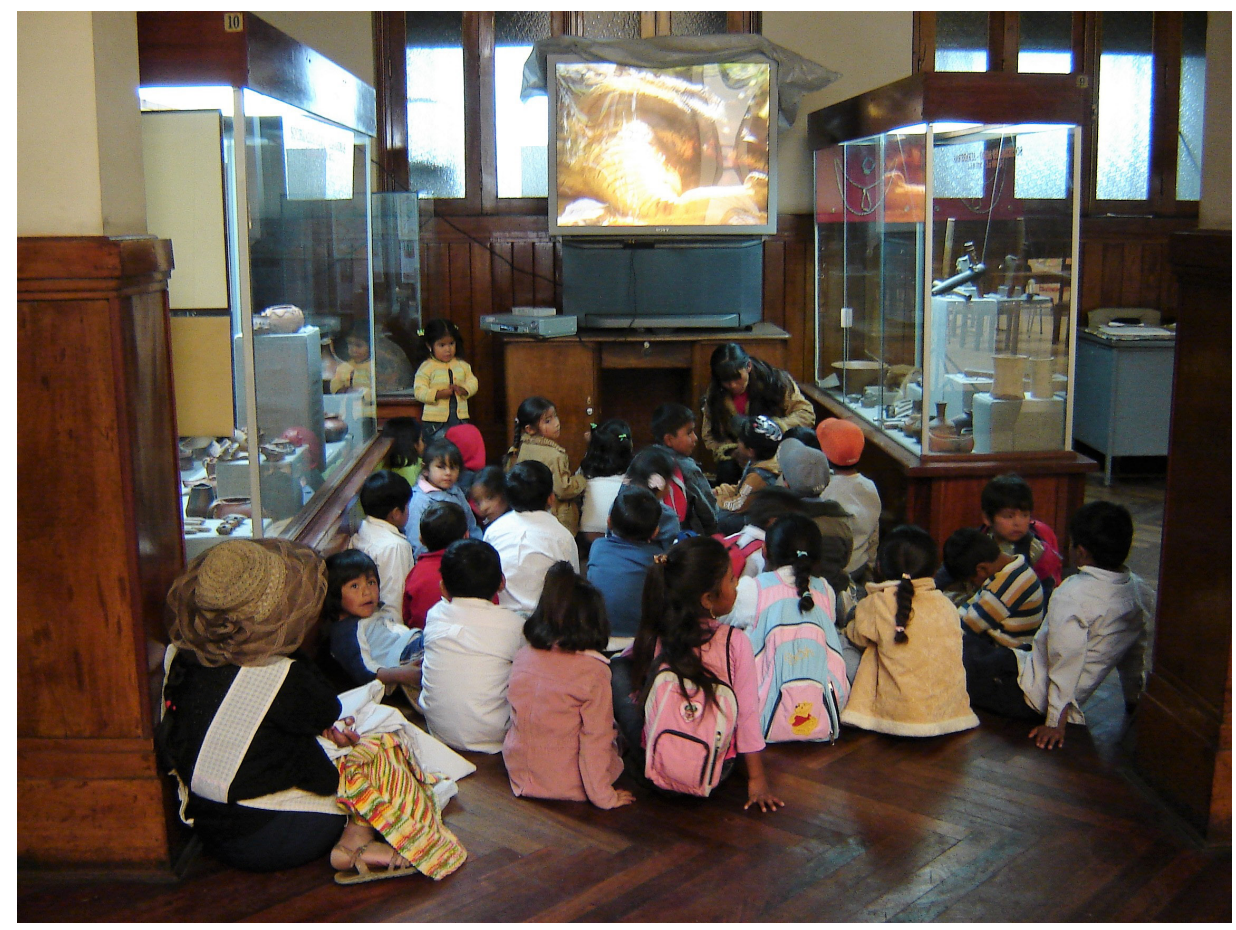

Figura 5. Trabajo con niños en una de las salas de exposición del INIAM, Cochabamba. Work with children in one of the exhibition rooms of INIAM, Cochabamba.

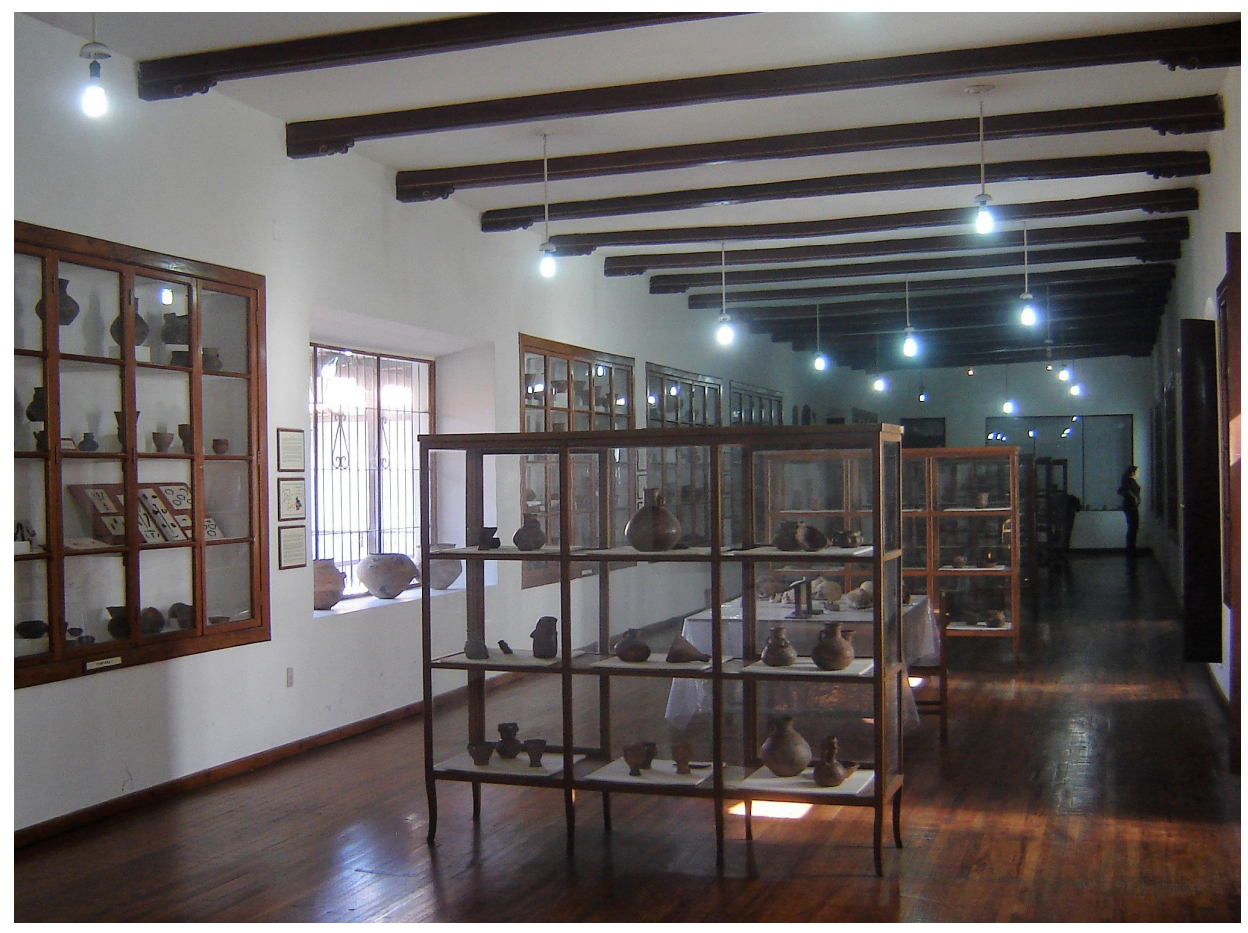

Figura 6. Museo Antropológico, Sucre.

Anthropological Museum, Sucre. 
cultura ni otros datos. Se exponen también, asociados por similitud, una serie de artefactos como torteras, wichuñas, cuentas de collar, y objetos de metal. No cuenta con programas específicos para el público pero desarrolla proyectos de investigación paleontológica y arqueológica, además de difundir sus colecciones a través de videos en YouTube y Facebook.

El Museo de Historia de la Universidad Gabriel René Moreno, con más de 20 años de antigüedad, se encuentra en Santa Cruz. La parte arqueológica consta de tres salas en las que se exponen objetos cerámicos de distintas regiones del departamento. Aunque existen paneles explicativos de piezas recuperadas en excavaciones de salvamento asociadas a la construcción de gasoductos, la exposición no cuenta con explicación alguna. No hay un sentido cronológico o de desarrollo regional ni nada parecido. No se tienen programas para los visitantes (Figura 7).

Finalmente está el Museo de la Universidad Tomás Frías en Potosí, que presenta distintas colecciones: mineralógicas, paleontológicas, arqueológicas y de arte, ajustándose más a los cánones de fines del siglo XIX. Las colecciones de la sala de arqueología están expuestas en vitrinas sin mayor información.

\section{Museos Municipales y Departamentales}

Los museos municipales fueron organizados en distintos momentos históricos por los gobiernos municipales, generalmente bajo el impulso individual de personalidades que estuvieron a cargo de dichas instituciones y con sensibilidad por la historia. Este tipo de repositorios se han convertido, en muchas ciudades, en espacios destacados para apreciar el patrimonio arqueológico e histórico.

En la ciudad de La Paz, el gobierno municipal cuenta con un complejo de museos que comprende, entre varios otros, al Museo de Metales Preciosos también conocido como Museo del Oro. Fue creado en 1979, albergando una importante colección prehispánica de objetos de metal y cerámica. Las piezas finas, elaboradas en oro, plata y bronce, son expuestas en vitrinas. Se constituyó sobre la base de donaciones de coleccionistas particulares como Mario Mercado, ex alcalde de la ciudad, y el joyero alemán Fritz Buck. Debido a ello, las colecciones no presentan un contexto específico, aunque los pequeños letreros que las acompañan incluyen información sobre período, técnica de elaboración y función (Figura 8).

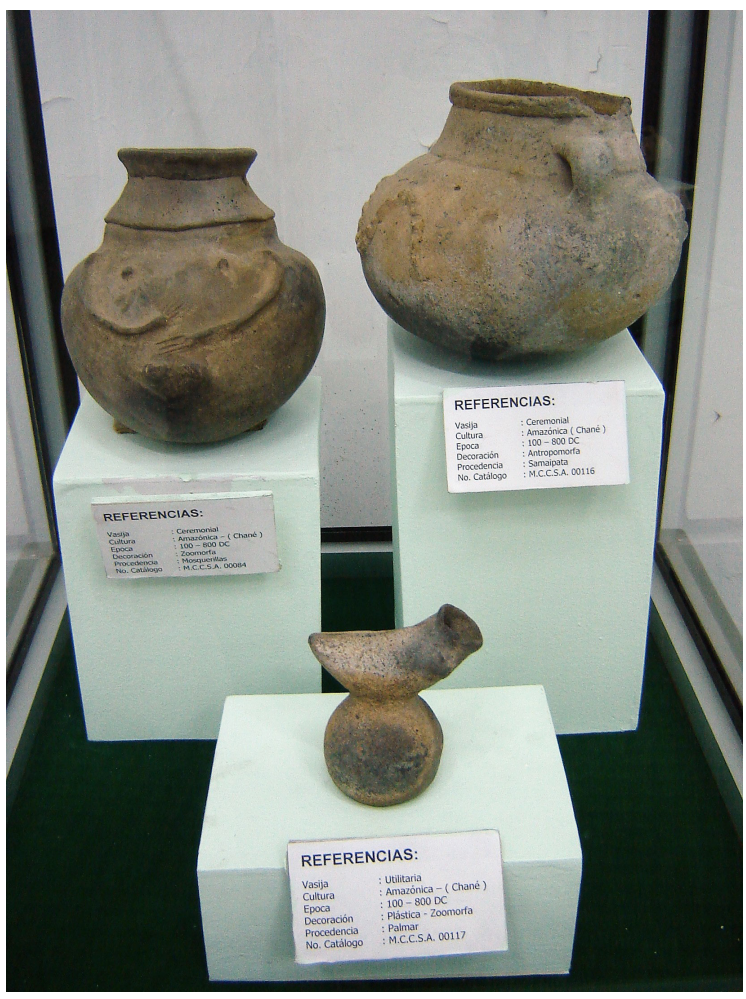

Figura 7. Exposición cerámica en el Museo de Historia, Santa Cruz. Ceramic exhibition at the History Museum, Santa Cruz. 


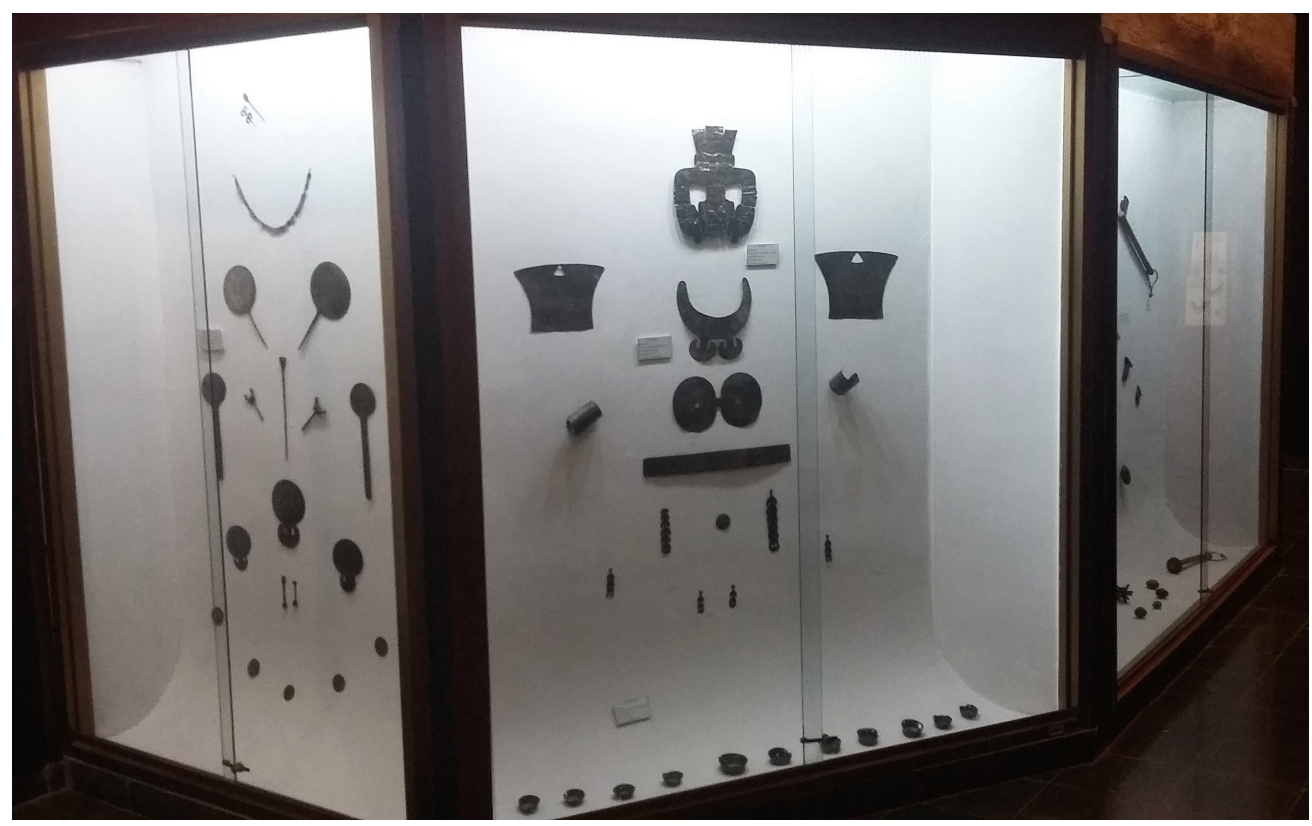

Figura 8. Piezas de plata en exhibición. Museo de Metales Preciosos, La Paz.

Silver objects in exhibition. Museum of Precious Metals, La Paz.

Se exponen conjuntos como el tesoro de San Sebastián, excavado en Cochabamba y probablemente perteneciente a Tiwanaku, con textos que informan sobre su contexto de hallazgo y una ilustración con la posible distribución de los objetos de oro como parte del atuendo del personaje. También se muestran en la Sala del Oro las diademas excavadas en los años 50 en Kalasasaya, Tiwanaku, pero sin mayor información, así como varias otras piezas. Muchas de ellas corresponden a contextos funerarios pero tampoco se hace explícito. La colección Buck posee cerámicas de varias regiones de Bolivia y está expuesta en una sala grande mostrando "las mejores piezas" pero sin textos guías, aparte de la filiación cultural y su cronología, lo que hace que no se conozcan en detalle sus características ni se transmita su importancia y significado. Este museo no posee programas para niños ni otro público.

Dentro de los museos municipales también está el complejo Pipiripi destinado a los niños y creado en los años 90. En este museo de carácter interactivo los niños aprenden y participan jugando: se disfrazan y pintan, realizan actividades como la venta tradicional en los mercados o tambos paceños, y también pueden aprender a hilar y tejer con técnicas prehispánicas como el sprang, tapiz, faz de urdimbre y anudado. Un pequeño espacio tiene representaciones de monolitos que hacen referencia al pasado prehispánico. Aunque la intención es transmitir conocimientos tradicionales estos, al parecer, no se hallan bien articulados a una historia prehispánica concreta.
En Oruro el Museo Nacional Antropológico Eduardo López Rivas, abierto en 1959, es el más importante a nivel departamental. En sus salas los objetos arqueológicos se exponen en vitrinas y espacios particulares, acompañados de dioramas y ejemplos etnográficos sobre la elaboración o función de los artefactos (Figura 9a y b). Dentro la museografía destaca la cultura Wankarani, con sus esculturas de llamas y cerámica, que exalta una identidad prehispánica regional con la que se identifican los habitantes de Oruro. Una serie de murales en la avenida sobre la que se encuentra el museo enfatizan el pasado y presente cultural de este departamento, siendo llamativo el que representa las formas de vida de la cultura Wankarani. En los últimos años, el museo ha organizado reuniones de arqueología como forma de relacionarse con investigadores que trabajan en el departamento de Oruro y difundir en su revista los resultados de su actividad.

En la ciudad de Trinidad, Departamento del Beni, desde el año 2004 existe el Museo Etnoarqueológico del Beni "Kenneth Lee", dependiente del gobierno del departamento. Cuenta con un amplio espacio al aire libre donde se reprodujo el paisaje de camellones de los Llanos de Moxos en la Amazonía, así como un edificio relativamente nuevo en el que están las colecciones y depósitos arqueológicos. La exposición, que ha sido recientemente renovada, muestra objetos cerámicos correspondientes a varios períodos que se asocian a fotografías de trabajos arqueológicos en las lomas o montículos de la región. También se exhibe una maqueta 

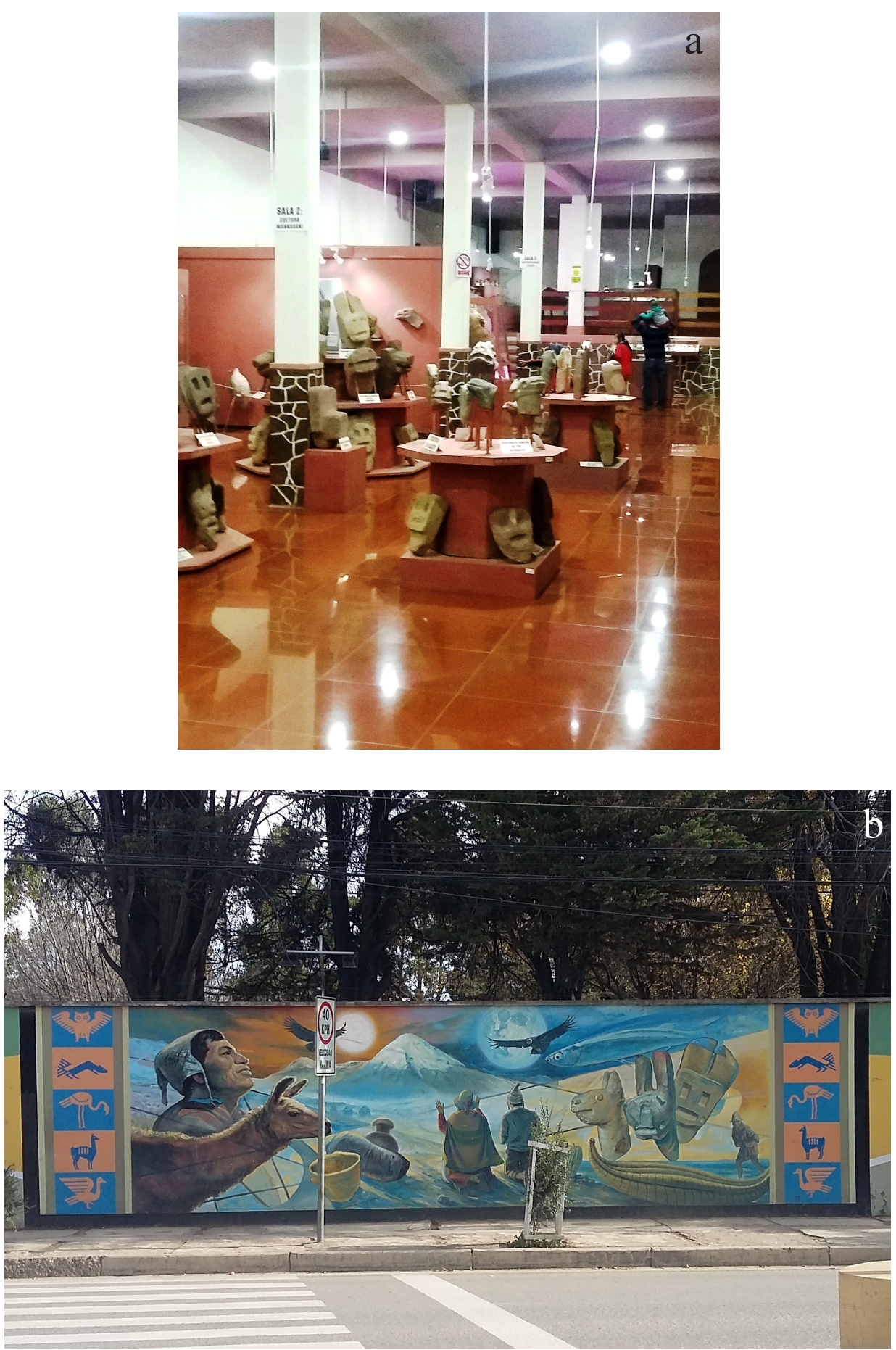

Figura 9 (a) Sala principal, Museo Eduardo López Rivas, Oruro. (b) Mural al exterior del Museo Eduardo López Rivas, Oruro.

(a) Main exhibition room, Eduardo López Rivas Museum, Oruro. (b) Mural on the outside of the Eduardo López Rivas Museum, Oruro. 
del paisaje cultural prehispánico en los Llanos de Moxos (Figura 10). No parecen existir programas con la comunidad.

En los valles cruceños de Santa Cruz existen varias localidades con museos municipales como los de Saipina, Vallegrande y Samaipata. En los dos primeros casos los museos se establecieron hace varios años con donaciones y colecciones particulares. Presentan al público vitrinas con piezas cerámicas, líticas y, en algunos casos, tejidos y restos óseos. A pesar de contar con catalogación de sus colecciones, la información para el visitante es pobre, limitándose a pequeños letreros que indican cultura y cronología. En Vallegrande se presentan fotos de sitios con arte rupestre que acompañan la exposición.

El Museo de Samaipata tiene mayor atención y flujo de visitantes debido a la cercanía del sitio arqueológico El Fuerte de Samaipata (declarado patrimonio de la humanidad) y a la presencia del Parque Nacional Amboró. El museo es amplio con jardines y salas de exposición en las que se muestran objetos cerámicos con la información sobre la cultura y su cronología. Sin embargo, este es otro caso en el que no se explota la información arqueológica disponible de las piezas,

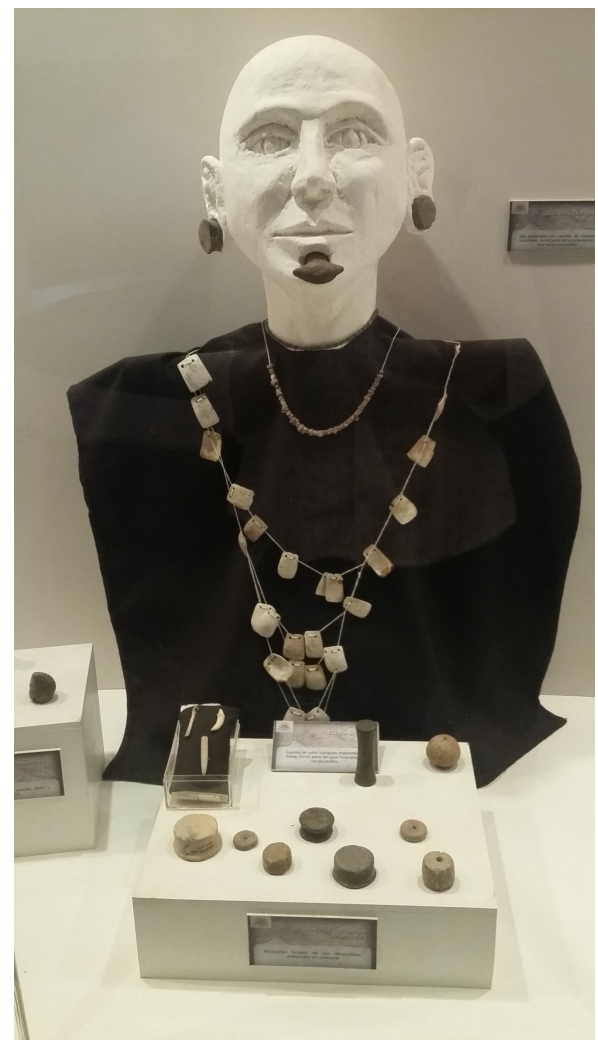

Figura 10. Personaje con ornamentos, Museo Kenneth Lee, Trinidad. Character with ornaments, Kenneth Lee Museum, Trinidad. muchas de las cuales corresponden a las excavaciones realizadas en El Fuerte y la región. Hacen falta mapas y otros paneles de texto, además de fotografías. El museo forma parte del tour que se realiza al complejo de El Fuerte y últimamente, un cambio en su dirección promovió un acercamiento mayor con el público y la comunidad a través de conferencias, talleres de cerámica, caminatas y trabajo con niños.

En Santa Cruz también se encuentra el nuevo Museo Inclusivo de San Carlos en los límites con el parque Amboró (Figura 11). Fue reinaugurado recientemente por el municipio y tiene el mismo sistema de presentar piezas con pequeños letreros explicativos, fotografías y mapas. La novedad es que en la nueva museografía trabajaron un arqueólogo, Luis Callisaya, un ceramista y un artesano para crear paneles sensoriales para invidentes y materiales que se puedan sentir con el tacto. También se diseñaron vitrinas para que gente en silla de ruedas pueda apreciar los objetos y se incorporaron sonidos, una mesa con aromas de café y otros productos para que las personas discapacitadas puedan tener una experiencia diferente (Museo San Carlos 2016). Se enfatizan temas como la interacción entre las tierras bajas y el occidente del país, contribuyendo a una visión más fluida sobre el pasado.

\section{Museos de Fundaciones Culturales y Otras Instituciones}

Además del Museo Nacional de Arte y el Museo de Etnografía y Folklore, la Fundación Cultural del Banco Central de Bolivia también tiene bajo su responsabilidad al Museo de la Casa Nacional de Moneda en la ciudad de Potosí, con colecciones de numismática, arte colonial, textiles y también una arqueológica. La Sala de Arqueología alberga objetos regionales tanto de Potosí como del oeste de Chuquisaca, que se constituyeron con las donaciones de investigadores como Dick Ibarra Grasso, Leo Pucher y otras personas como Porfirio Miranda, párroco de San Lucas, Chuquisaca. La colección consta de objetos cerámicos, material lítico y una buena selección de tejidos del área Yura. A pesar de su importancia, estos materiales se hallan expuestos en vitrinas con pequeños letreros sobre las culturas que no terminan de transmitir su significado y ni siquiera con un orden cronológico. Hace falta contextualizar las colecciones (Figura 12). Aunque la naturaleza de las colecciones le da a esta sala un enfoque regional distintivo, este valor no es aprovechado a nivel museográfico y la historia prehispánica no se transmite de manera clara al visitante.

En Sucre se encuentra el Museo de Arte Indígena de la Fundación ASUR, inaugurado en 1986 por Verónica Cereceda como parte de un programa de renacimiento del arte textil indígena en las regiones 


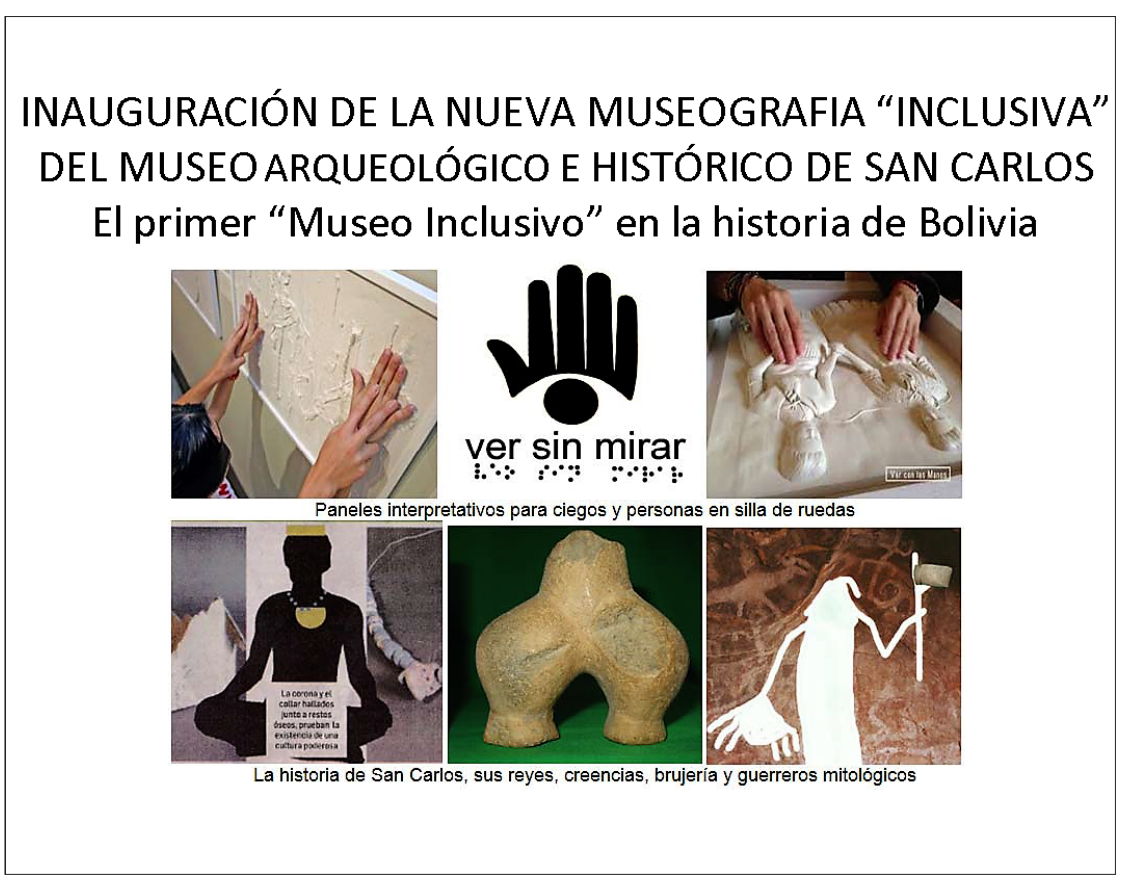

Figura 11. Presentación del Museo San Carlos, Santa Cruz (cortesía Luis Callisaya)]. Presentation of the San Carlos Museum, Santa Cruz (courtesy Luis Callisaya).

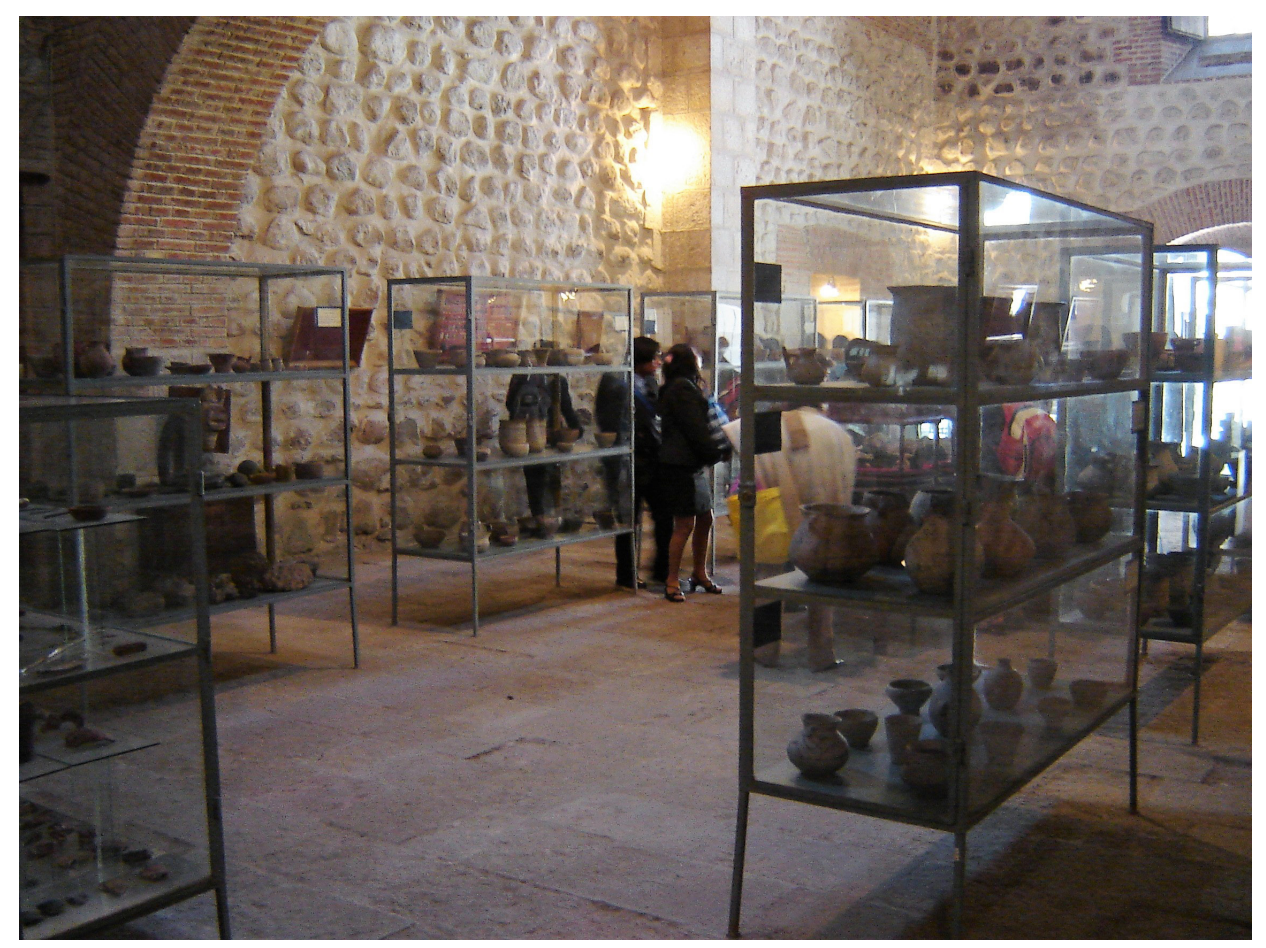

Figura 12. Sala de Arqueología, Casa Nacional de Moneda, Potosí.

Archaeology exhibition room, Casa Nacional de Moneda, Potosí. 
Jalq'a y Tarabuco en Chuquisaca. Aunque se enfoca en áreas y estilos textiles contemporáneos del sur de Bolivia, exhibe textiles e instrumentos de hilar y tejer prehispánicos, resaltando un conjunto de piezas variadas que provienen de las cuevas funerarias de Pulacayo en Potosí (Figura 13). En las distintas salas se transmite el nexo existente entre la tecnología prehispánica y la contemporánea además de estilos textiles regionales. El museo está vinculado con comunidades de tejedoras y tiene programas de apoyo en varias regiones, además de investigaciones etnográficas sobre los contextos de producción de los tejidos y sus repertorios iconográficos, información que se difunde mediante libros. Destaca la presencia de tejedoras de comunidades de los alrededores de Sucre, como Potolo y Tarabuco, que enseñan a los visitantes de forma directa sus formas de tejer, enfatizando la importancia de estas localidades de práctica textil del sur de Bolivia.

\section{Museos Regionales}

Los museos regionales en Bolivia fueron creados desde la década de 1950 en varias regiones del país, muchos de ellos como parte de los centros de investigación regionales que estuvieron bajo la tutela del Instituto Nacional de Arqueología (INAR).

Partiendo del altiplano paceño tenemos el Museo Regional de Tiwanaku, creado a fines de los años 50 y uno de los más importantes del país. Inicialmente funcionó en el antiguo hotel de Tiwanaku y a inicios de los años 90 se construyó una nueva infraestructura con dos bloques, el de objetos cerámicos y el de líticos (Figura 14). La concepción museográfica fue pensada para exponer los objetos por tipo de soporte sin una presentación contextual, lo que le resta sentido a la colección. Predomina un criterio tipológico que no incluye la proveniencia ni contexto de las piezas, en su mayor parte producto de las investigaciones realizadas en el lugar y sobre las que podrían darse explicaciones detalladas. El museo es visitado por muchos turistas de todas las edades y no existe mayor información. Se han adaptado paneles sobre metalurgia en un sector que presenta información sobre las grapas metálicas, así como maquetas de sukakollus o campos de cultivo elevados y productos agrícolas. En general, el visitante se lleva una impresión de lo que es Tiwanaku pero el museo no presenta información sobre su conocimiento actual ni explota la rica información contextual que tiene el $95 \%$ de sus piezas y que abarca los últimos 60 años de investigación sobre el sitio. El año 2018 se inició el proceso para la construcción de un nuevo museo regional, con una museografía y orientación renovada, partiendo de reuniones de consulta a distintos actores involucrados en la investigación sobre Tiwanaku, la gestión de museos y la relación con las comunidades del valle de Tiwanaku.

Otro museo regional en el departamento de $\mathrm{La}$ Paz es el de Copacabana, situado en la comunidad

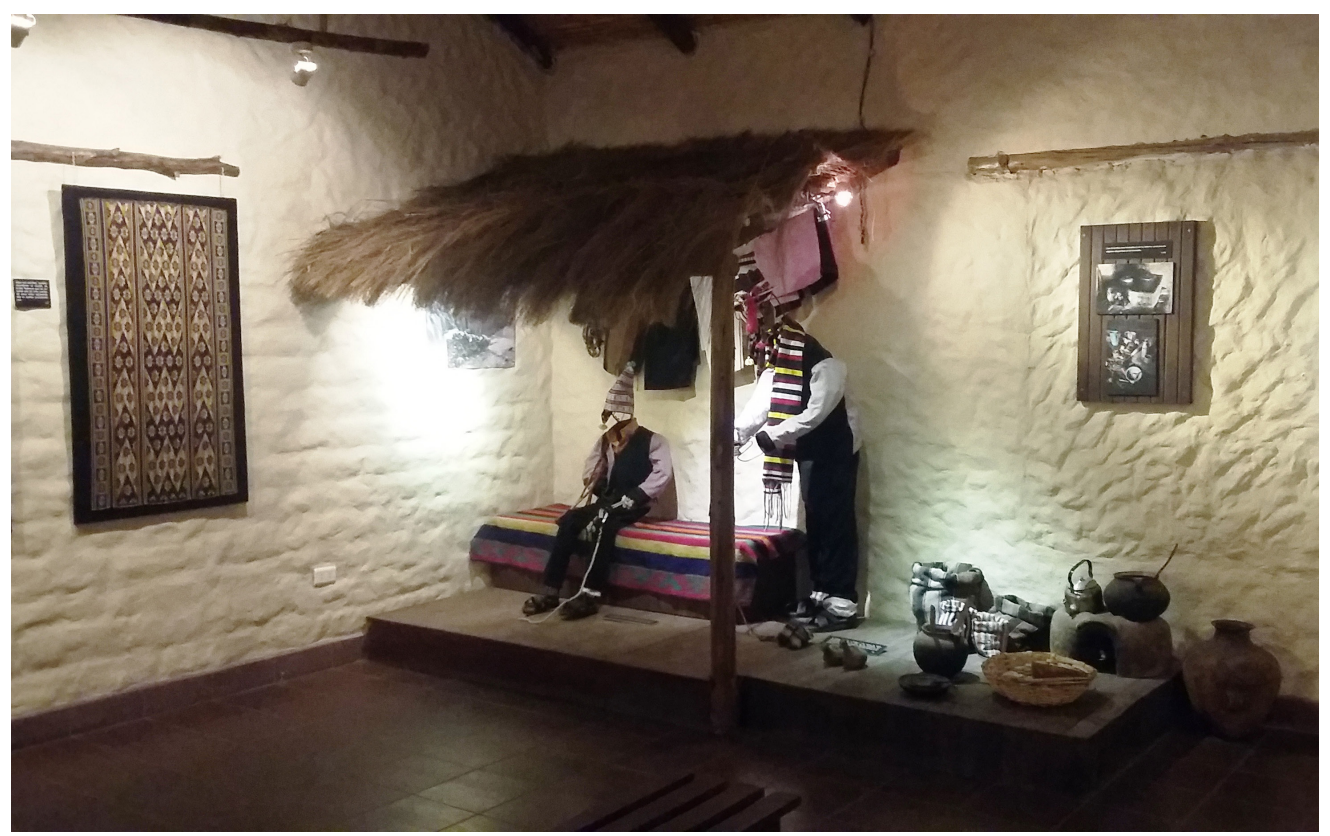

Figura 13. Sala de exposición del Museo de Arte Indígena de la Fundación ASUR, Sucre.

Exhibition hall of the Museum of Indigenous Art of the ASUR Foundation, Sucre. 


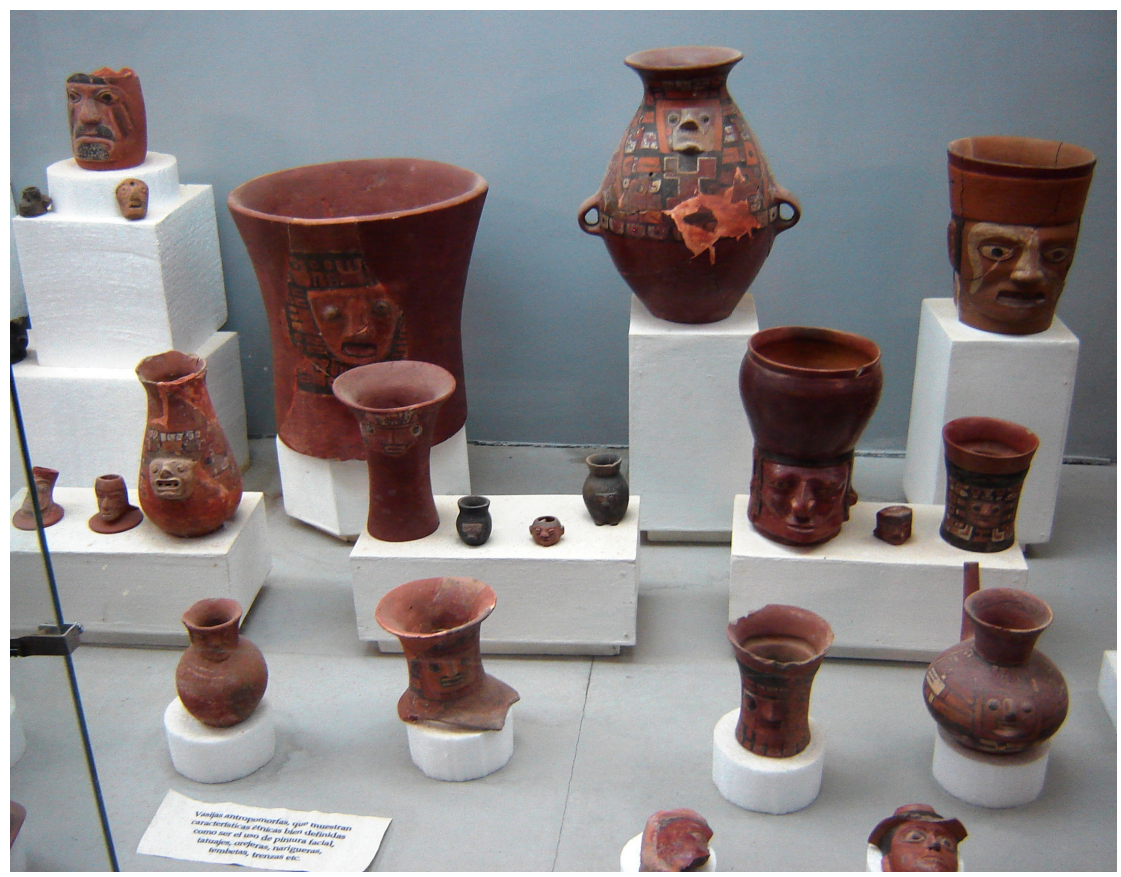

Figura 14. Exposición de cerámica, Museo Regional Tiwanaku, La Paz.

Ceramic exhibition, Tiwanaku Regional Museum, La Paz.

de Kusijata. En este museo, muy abandonado, se muestran diversos objetos cerámicos de varias épocas. Nuevamente, aparte de cultura y periodo, poco es lo que el visitante puede entender contextualmente de ellos. El abandono se refleja también en la relación misma con la comunidad que, si bien administra el museo, no tiene la capacitación ni los recursos para mantenerlo limpio y con información adecuada para los visitantes, aunque se cobre el ingreso. Entre otros museos regionales también se pueden mencionar los museos de Iskanwaya, en el norte de La Paz, y de Samaipata, en Santa Cruz, ya descrito en el apartado de museos municipales.

\section{Museos comunitarios}

Los museos comunitarios en Bolivia nacen, en buena parte de los casos, del influjo de un boom del turismo desde los años 90 y han incorporado, en distintos grados, algunos conceptos básicos de la nueva museología, como la relación del ser humano y su medioambiente social y natural. Asimismo, las comunidades ven en estos espacios una manera de presentar sus recursos culturales para acceder a beneficios económicos (De Carli 2003:5). Han surgido de distintas maneras, a veces ligados a proyectos de investigación arqueológica que, en su última fase, se comprometen a dejar un museo a la comunidad con los materiales producto de sus trabajos; otras veces nacen como iniciativas netamente comunitarias al vivir cerca de sitios arqueológicos y/o ver un incremento del turismo en la región, como en el caso del Salar de Uyuni y su entorno próximo.

Dentro de este tipo de recintos se encuentra el Museo de sitio de la Isla Pariti, abierto en 2005, que se constituyó con base en las colecciones principalmente cerámicas extraídas de dos singulares pozos de ofrenda, mismos que fueran excavados en esta isla por una misión finlandesa-boliviana entre los años 2004 y 2006 (Korpisaari y Sagárnaga 2007; Villanueva 2007). Todos los materiales extraídos corresponden a la última fase de Tiwanaku (900-1100 DC) y tienen un valor excepcional por estar completas o casi completas, mostrando el rico mundo simbólico y ritual de esta cultura. La museografía es modesta y se centra en mostrar la diversidad de piezas acompañadas de pequeños letreros explicativos, además de fotografías y dibujos de las excavaciones. Aún requiere incorporar mayor información sobre los contextos y darle sentido a los objetos que se exponen de manera separada y esquemática. Existen importantes publicaciones sobre este material cuya información no está incorporada en la exposición. Por otra parte, la cantidad de visitas que recibe es limitada, considerando la importancia que tienen sus materiales para el entendimiento de Tiwanaku. Hace falta un programa amplio de difusión para generar un interés por asistir al lugar. En este sentido, el reciente apoyo del MUSEF será significativo para la consecución de planes futuros.

El Museo Comunitario Abierto Arqueológico de Piñami, en el valle central de Cochabamba, abarca 
un montículo que fue construido y habitado desde el periodo Formativo hasta el Horizonte Tardío (800 AC-1535 DC). Queda una pequeña parte de toda su extensión original ya que fue destruido por la expansión urbana. Fue investigado por Ricardo Céspedes, Karen Anderson, Zulema Terceros y su equipo, bajo el patrocinio institucional del Instituto de Investigaciones Antropológicas y Museo Arqueológico de la Universidad Mayor de San Simón (Anderson 2007; Céspedes 2000). Con las donaciones de diversas instituciones, en el transcurso de los años se fue formando un museo de sitio que muestra los sectores excavados y un pequeño jardín botánico (Figuras 15a y 15b). Se capacitó a guías locales que explican las características del sitio, siendo importante el trabajo con colegios. También existe un video en internet con las características del sitio y una página de Facebook. Este museo recibe visitas de colegios y trabaja con la comunidad de manera más sostenida. Zulema Terceros (comunicación personal 2016) menciona que cuando los visitantes llegan al museo, especialmente los niños, lo único que ven son perfiles de tierra pero, una vez que reciben la explicación de la estratigrafía vinculada a fotos de la excavación y las piezas, quedan sorprendidos con la información. El museo se sustenta con donaciones y las entradas de los visitantes.

Otro caso en Cochabamba es el museo comunitario de Tablas Monte, una localidad del Municipio de Colomi, que se encuentra en un bosque nublado bajando hacia el Chapare, a unos 1800 msm. En esta comunidad se encuentran sitios arqueológicos y extensos sistemas agrícolas de cultivo que fueron aprovechados para la captación de humedad a lo largo de la época prehispánica (Sánchez Canedo 2008). Tales sistemas relacionados con redes viales fueron estudiados entre
2004 y 2010 y, a partir de un trabajo con la comunidad, se estableció un museo de sitio asociado con su escuela donde se plasmaron los resultados de los trabajos de investigación en paneles explicativos junto a las vitrinas. También se elaboraron un video y un boletín (Sánchez y Ticona 2010). El impacto del museo en la comunidad ha sido, como en otros casos, limitado. La distancia con la ciudad impide un movimiento fluido de visitantes. Notas de prensa de diciembre de 2016 señalan que el museo se encuentra abandonado y cerrado a pesar de los esfuerzos realizados para su apertura y funcionamiento.

En elárea rural de Oruro existen varios museos como el de Huari y el de Quillacas, que fueron establecidos bajo un acuerdo de cooperación con el Instituto de Investigaciones Antropológicas y Arqueológicas (IIAA) de la Universidad Mayor de San Andrés. Sus colecciones se conformaron con donaciones locales y materiales obtenidos en trabajos arqueológicos del IIAA entre los años 2001 y 2008. Los objetos se exponen en vitrinas con pequeños letreros. Estos museos fueron establecidos en 2005 con la esperanza de atraer turistas, sin embargo, no han funcionado de la manera esperada y se hallan cerrados casi todo el tiempo, no cumpliendo la función de difundir la historia regional. La competencia del DAKAR, que se realiza en enero de cada año, es un importante aliciente para que la gente que asiste al evento visite estos museos.

En los últimos años se han ido creando una serie de museos comunitarios por todo el país con el apoyo de ONGs y otras instituciones que promocionan el turismo. Buena parte de ellos tiene un componente arqueológico que en muchos casos se muestra bien organizado, como el museo de Guaqui donde trabajaron especialistas, y en otras ocasiones se presenta según las ideas que la gente de las comunidades tiene sobre los

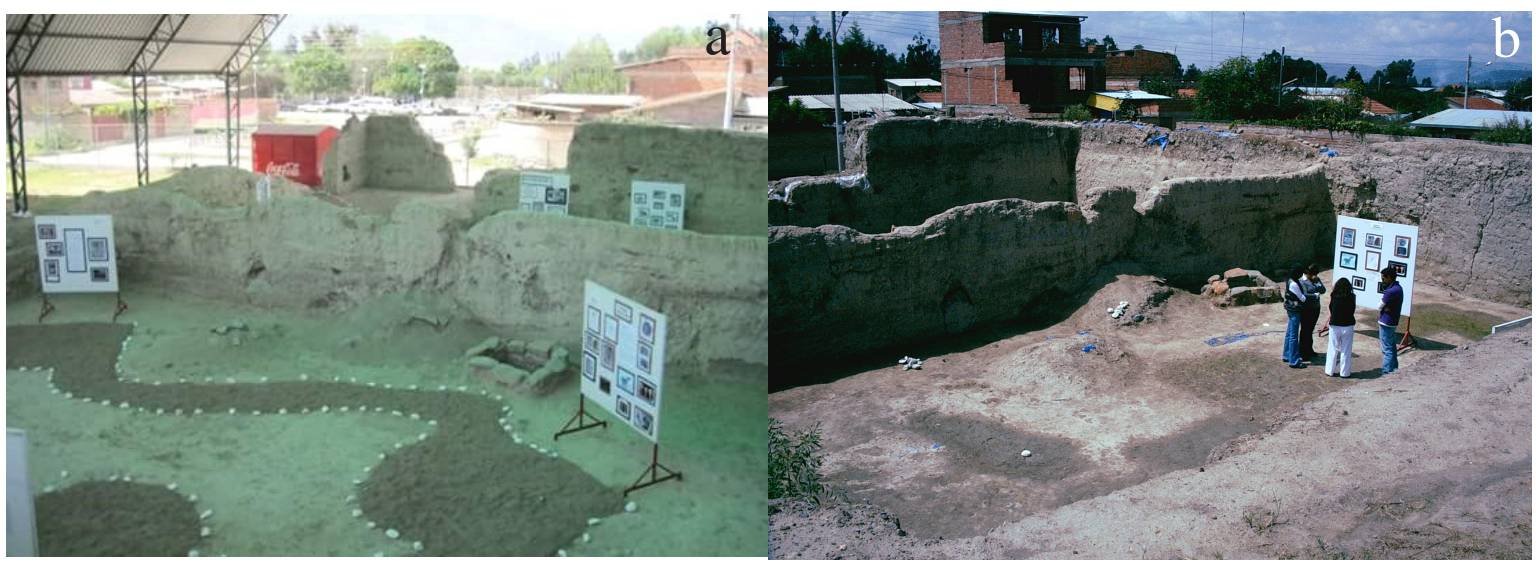

Figura 15 (a) Museo abierto de Piñami, Cochabamba (cortesía Zulema Terceros). (b) Museo abierto de Piñami, Cochabamba 2007 (cortesía David M. Pereira).

(a) Open Museum of Piñami, Cochabamba (courtesy Zulema Terceros). (b) Open Museum of Piñami, Cochabamba 2007 (courtesy David M. Pereira). 
restos materiales. Desde hace varios años existe una red de museos comunitarios que tiene como objetivo apoyar la creación de museos desde la misma comunidad, como una herramienta para que reafirme la posesión de su patrimonio material y simbólico a través de sus propias formas de organización. En teoría desde allí se debería construir un autoconocimiento colectivo, fomentar la creatividad y reforzar las identidades locales, además de crear un puente de intercambio con otras comunidades, mejorando la calidad de vida de los miembros. En la práctica esto se cumple con distintos grados de éxito y las redes no terminan de despegar ni consolidarse. Como el trabajo es básicamente voluntario y los recursos no son abundantes, estas iniciativas tienen ciclos y a veces tiempos limitados de vida.

\section{Discusión}

Con esta breve síntesis sobre distintos tipos de museos en Bolivia se pueden puntualizar varios aspectos comunes en los museos con contenido arqueológico. Principalmente se aprecia que en los museos bolivianos aún prima un pensamiento tipológico y tradicional. Es decir, que predominan visiones relacionadas con el objeto aislado o con la historia cultural, en las que se prioriza la exposición de objetos separados por tipo de material (cerámica, lítica, textiles, entre otros), señalando la filiación cultural, período y a veces función. Este tipo de presentación se ha mantenido a través del tiempo sin dar un salto cualitativo hacia formas más modernas de exposición, como las planteadas por la nueva museología y en la declaración de la Mesa Redonda de Santiago de Chile (1972). Esto es patente en los museos más antiguos con una larga tradición en este tipo de exposiciones, lo que dificulta cambiar de perspectiva. Los formatos de presentación parecen haberse institucionalizado y "cobrado cierta vida propia", por lo que un cambio en la museografía es poco probable. Los intentos por modificar las formas de presentación y generar una visión mucho más completa, que aproxime a los visitantes a las formas de organización y vida en el pasado, son tímidos y muchas veces limitados por la disponibilidad de recursos económicos. Una notable excepción es el Museo Nacional de Etnografía y Folklore que ha optado por una renovación plena de sus exposiciones, incorporando el concepto de cadenas operativas además de recoger los cuestionamientos de la sociedad indígena y sus visiones sobre los materiales y la vida social de los objetos.

La visión que se presenta del pasado es aún muy estática, una colección de objetos que no transmite claramente la historia de los pueblos, sus procesos diversos, los cambios y continuidades a nivel local y regional ni su relación con el entorno natural. Temas como la interacción entre sociedades y regiones no son abordados adecuadamente, lo que dificulta explicar la conformación de identidades culturales y sus implicaciones para las sociedades actuales.

Se desaprovecha o no se toma en cuenta el conocimiento detallado que circula en los ámbitos académicos. Los ejemplos más claros son los de los museos nacionales, universitarios y del museo regional de Tiwanaku, cuyas colecciones poseen la información necesaria para ofrecer información abundante. Las personas a cargo de los museos, muchas veces arqueólogos, no terminan de romper con esquemas de presentación tradicionales o no cuentan con la formación suficiente para hacerlo.

En términos de vinculación con el público y la comunidad en general, no se han desarrollado programas que permitan lograr una identificación con el pasado que genere una conciencia colectiva y una identidad en torno a él, con distintos grados de apropiación. Algunos museos hacen uso de herramientas como YouTube o Facebook para generar interés y transmitir información sobre sus colecciones y actividades. Son los casos del MUSEF, el INIAM, el Museo de Metales Preciosos de La Paz o el Museo comunitario de Piñami. Se debe acotar que los museos que dependen de fundaciones como la del Banco Central de Bolivia o entidades privadas están en mejores condiciones para realizar programas de interacción y difusión, como el MUSEF y el Museo de Arte Indígena.

En los museos del área rural, principalmente comunitarios, tampoco se ha logrado esta identificación. Muchas veces las comunidades se interesan más por el turismo y no por su pasado: el patrimonio arqueológico es visto como un recurso para generar fondos más que como parte de una historia que se aprecie a profundidad. La Red Plurinacional de Museos Comunitarios de Bolivia, que incorpora muchas veces colecciones arqueológicas, ha estado trabajando en los últimos años para generar lazos entre museos, compartir experiencias, impartir talleres de capacitación y fortalecer su organización. Sin embargo, sus acciones parecen ser aún limitadas y estar en una fase de organización.

Considerando los puntos arriba mencionados cabe preguntarse, ¿están siendo los museos en Bolivia transmisores de conocimiento y formadores de valores sobre un pasado que penetre en el imaginario colectivo y refuerce las identidades en varios niveles?

A un nivel general los museos transmiten cierta información y dan una impresión sobre el pasado prehispánico. El tema de las culturas arqueológicas y su periodización está en casi todos ellos. Sin embargo, la forma como se muestra a las sociedades pasadas no deja de ser fragmentada ni logra presentar la diversidad y riqueza histórica de un pasado altamente complejo. Los museos nacionales, dependientes del Estado, son los que históricamente han logrado articular con mayor éxito un discurso nacionalista en torno a la región 
andina y particularmente a Tiwanaku como parte de un pasado común a la sociedad boliviana. Sin embargo, la diversidad cultural prehispánica aún no ha podido ser presentada y transmitida de una manera coherente dentro de la nueva visión del Estado Plurinacional étnica y culturalmente diverso.

Urge un cambio radical en las formas de presentación de casi todos los museos: deben pasar de ser repositorios a convertirse en espacios de mayor contacto e interacción con el público, ya sea a través de una museografía renovada o de actividades que promuevan la participación de los visitantes. Los niños, quienes están formando su visión sobre la historia y su identidad, debieran ser un grupo privilegiado y priorizado dentro de los museos. El caso del INIAM es tal vez el único que ha logrado sostener un programa a lo largo del tiempo para transmitir los principios básicos de la arqueología. Los programas del MUSEF en este rubro habrán de ser evaluados a futuro.

Aunque el factor económico y técnico es el que prima a la hora de realizar cambios en las exposiciones, la transmisión de información puede ser menos costosa si se vincula con internet. La atracción del público, por tanto, no solamente está en las visitas a la institución, sino en salir de ella de una manera más dinámica e interactiva. Esto se refleja en las opiniones vertidas por un grupo entrevistado de 60 personas de varias edades, entre 12 y 77 años, y, de diversa formación profesional. Muchos de los más jóvenes opinan que los museos son aburridos y que no se aprende nada. Por otra parte, los adultos señalan que visitan los museos de forma aleatoria sin un interés particular por el tema arqueológico y, lo que aprenden sobre él se limita a la poca información que acompaña a las piezas en exhibición. Algunos no ven la utilidad práctica de conocer el pasado, mientras que otros sugieren que los museos tengan folletos y revistas especializadas para la difusión de sus colecciones e investigaciones que permitan ampliar el conocimiento de lo que se presenta en las salas. Por otra parte, en muchos no hay quien guie y explique las exposiciones de manera clara y concreta, por lo que no se entiende lo presentado.

Las consecuencias de no incentivar la visita a los museos desde el colegio de una manera sostenida e integral, pero también el que estos ofrezcan actividades didácticas y atractivas, se advierten también en esta consulta.

\section{Conclusiones}

Los datos presentados en este trabajo nos muestran, contradictoriamente, que siendo Bolivia un país con un vasto legado prehispánico bastante estudiado en los últimos 30 años, y a pesar de tener numerosos museos con esta temática, sus exposiciones no lo han plasmado adecuadamente. No se aprovecha la información arqueológica disponible y los textos que se presentan son muy limitados, no permiten ampliar el conocimiento más allá de un esquema tipológico con un fuerte contenido estético.

Esta forma de presentación fue copiada de los museos más antiguos a los más modernos, tanto en las capitales como en otras ciudades y localidades. Existen contadas excepciones que complementan sus exposiciones con dioramas, dibujos y otros recursos. Sin embargo, aún faltan visiones más holísticas que transmitan procesos y contextos sociales, como lo han logrado museos en países vecinos (Museo Arqueológico San Miguel de Azapa en Arica, Chile y Museo Contisuyo en Perú).

Los museos transmiten una visión de objetos "bonitos" y aislados que hace que las personas no terminen de entender la importancia del pasado en su vida actual y su identidad, sobre todo en los centros urbanos. Claramente existen fallas y limitaciones en las formas de transmitir conocimiento y de lograr una apropiación por parte del público y de distintas comunidades.

Las actividades para niños, muy reducidas, están funcionando en términos de lograr la comprensión de ciertos principios arqueológicos y que se interesen por el pasado, pero aún falta mucho para hacer estas actividades sostenibles y de impacto. No bastan unas pocas visitas a los museos durante la vida colegial, deben ser constantes para lograr mejores resultados.

Los museos comunitarios tienen el potencial para lograr una apropiación más local de un pasado, tal vez más familiar, pero aún deben consolidar sus propios procesos. En estos espacios no solamente es importante la visión de los especialistas sino las voces de los propios involucrados, quienes tienen un legado muy rico de saberes tradicionales, sobre todo entre las personas mayores.

Aunque el balance presentado en este trabajo tiende a ser negativo, se han logrado ciertos niveles de identificación con un pasado común entre los bolivianos. Particularmente, me refiero al fenómeno de Tiwanaku y de las culturas de los Llanos de Moxos. En el primer caso, el interés del Estado por asociarse con un pasado glorioso desde fines del siglo XIX, y más enfáticamente a partir de los años 50, ha permeado en la población que sî reconoce a Tiwanaku como parte de un pasado general. Por lo menos en el occidente del país, cuando se pregunta sobre un museo o tema de arqueología se hace referencia al museo Tiwanaku y a la apropiación simbólica de este pasado, aunque muchas veces distorsionado. Esta apropiación se refleja en la arquitectura de la ciudad de La Paz con motivos tiwanakotas, como el Monoblock de la Universidad Mayor de San Andrés y otros edificios diseñados por arquitectos reconocidos como Emilio Villanueva o Juan Carlos Calderón. Versiones más 
populares, se manifiestan en edificios con ornamentos de estilo tiwanakota, como los famosos "cholets", además de monolitos y puertas del sol colocados en plazas de ciudades como El Alto y pueblos como Tiahuanaco mismo. Los Puma Katari, buses del municipio paceño, presentan al felino sonriente de inspiración Tiwanaku como parte de sus diseños. En la región de Tiwanaku este tipo de apropiación se hace más evidente, siendo comunes en los edificios la ornamentación con frisos y molduras con motivos del estilo mencionado, sobresaliendo entre todos ellos la cruz cuadrada o andina.

En el caso de los Llanos de Moxos y de la gente de Trinidad, en el oriente boliviano, el apoyo político a la identidad local también generó cierto conocimiento y valoración de los campos de cultivo elevados, las lomas y otras obras en tierra de la época prehispánica, pero que no se asimila como parte de un pasado propio. El orgullo está en identificar que existió una alta cultura en la región que dejó un legado visible en los paisajes antrópicos de las llanuras de Moxos.

En síntesis, las apropiaciones más notorias y duraderas del pasado prehispánico surgen de discursos y narrativas-las épicas en arqueología, como señala Albarracin-Jordan (2007)- que mezclan el dato histórico con versiones pseudocientíficas que responden a intereses políticos. Esto es tan claro que en el cuadro de línea de tiempo del Museo Regional Tiwanaku se representa toda la historia prehispánica, terminando con Evo Morales como la representación actual de ese proceso histórico glorioso.

A comienzos del siglo XXI los museos en Bolivia requieren un cambio significativo en su orientación y la forma de presentación de sus colecciones. Es necesario contar con profesionales capacitados en temas de museografía para una renovación de las exposiciones, que incorpore información actualizada sobre las sociedades pasadas y sus procesos de interacción y conformación de identidades. Por otra parte, el diálogo horizontal con la sociedad en los ámbitos urbanos y rurales y con los arqueólogos, generadores de los datos científicos, es de crucial importancia para plasmar información actualizada, recoger demandas y construir formas de transmisión de valores ajustadas a la realidad de la sociedad boliviana y sus distintos niveles de identificación social. Como bien manifestaron varias de las personas entrevistadas, la presentación de objetos aislados es una forma de transmisión fría que no tiene un impacto favorable. La renovación constante de las exposiciones y las presentaciones interactivas constituirían vehículos alternativos para lograr una relación más dinámica con el público y brindar elementos de identificación colectiva.

La información arqueológica producida en las últimas décadas acerca de la diversidad en la estructura social y económica de las sociedades prehispánicas, sus trayectorias históricas y los elementos materiales que expresan identidades regionales y locales, además de formas particulares de entender el mundo y relacionarse con él, debieran constituir los ejes a partir de los cuales se busque incorporar y representar la diversidad social y cultural pasada. Esto ayudará a comprender las raíces de estos aspectos, sus cambios y continuidades a través del tiempo y su importancia para la consolidación de imaginarios colectivos nacionales, regionales y locales en la sociedad boliviana actual.

Agradecimientos: Al Instituto de Investigaciones Andinas (IAR) a través de Heather Lechtman y Gary Urton por su invitación a participar del Taller Representaciones Actuales de las Culturas Precolombinas en los Museos Andinos. A los participantes del evento por sus comentarios y observaciones que ayudaron a mejorar la calidad del manuscrito. A Zulema Terceros y Luis Callisaya por compartir información sobre los museos de Piñami y San Carlos, y a David M. Pereira por sus fotografías y comentarios. A todas las personas que con sus opiniones contribuyeron al desarrollo de este trabajo.

\section{Referencias Citadas}

Albarracin-Jordan, J. 2007. La Formación del Estado Prehispánico en los Andes. Origen y Desarrollo de la Sociedad Segmentaria Indígena. Fundación Bartolomé de las Casas, La Paz.

Anderson, K. 2007. Tiwanaku influence on local drinking patterns in Cochabamba, Bolivia. En Drink, Power, and Society in the Andes, editado por J. Jennings y B.J. Bowser, pp. 167199. University Press of Florida, Gainesville.

Boero Rojo, H. 1993. Bolivia Mágica. Editorial Vertiente, La Paz.

Céspedes, R. 2000. Excavaciones arqueológicas en Piñami. Boletín del INIAM-Museo Serie Arqueología Boliviana 9.
De Carli, G. 2003. Vigencia de la nueva museología en América Latina: conceptos y modelos. Revista ABRA.

Declaración de la Mesa Redonda de Santiago de Chile 1972. http://www.mesadesantiago.info/?page_id=41

Instituto de Investigaciones Antropológicas y Museo Arqueológico (INIAM). 2001. 50 años salvando el pasado para el futuro. Boletín Especial INIAM-Museo, INIAMUMSS, Cochabamba.

Korpisaari, A. y J.A. Sagárnaga 2007. Investigaciones arqueológicas en la isla Pariti, Bolivia: Temporadas de campo 2004, 2005 y 2006. Chachapuma Revista de Arqueología Boliviana 1:7-30. 
Rattunde, N.M. 2017. ¿Museos Plurinacionales? Transformaciones en los Museos Nacionales en Bolivia. Tesis de Maestría. Rheinische Friedrich-Wilhelms-Universität Bonn, Bonn.

Museo San Carlos 2016. Inauguración de la Nueva Museografía "Inclusiva" del Museo Arqueológico e Histórico de San Carlos, el Primer "Museo Inclusivo" en la Historia de Bolivia. Ayuda Memoria para Medios de Comunicación, Santa Cruz.

Nicolas, V. y P. Quisbert 2014. Pachakuti: El Retorno de la Nación. Estudio Comparativo del Imaginario de Nación de la Revolución Nacional y del Estado Plurinacional. La Nación Boliviana en Tiempos del Estado Plurinacional. Fundación PIEB, La Paz.

Ponce Sanginés, C. 1980. Panorama de la Arqueología Boliviana. Editorial Juventud, La Paz.

Sánchez Canedo, W. 2008. Inkas, “Flecheros” y Mitmaqkuna. Cambio Social y Paisajes Culturales en Los Valles y en Los Yungas de Inkachaka/Paracti y Tablas Monte (CochabambaBolivia siglos $X V-X V I)$. Uppsala Universitet, Uppsala.

Sánchez Canedo, W. y M. Ticona 2010. Tablas Monte. Los Yungas de Cochabamba: Prehistoria, Cultura y Medioambiente en el Bosque de Neblina, Cochabamba.

Villanueva Criales, J. 2007. Las escudillas del Rasgo 1 en la isla de Pariti: Interpretación y consideraciones desde un enfoque iconográfico. Chachapuma Revista de arqueología boliviana 1:53-63.

Villanueva Criales, J. 2019. De lo precolombino a las cadenas operatorias. El Museo Nacional de Etnografía y Folclore (MUSEF) de Bolivia en perspectiva histórica. Chungara Revista de Antropología Chilena 51 (2):201-217.

\section{Notas de prensa}

Amado Romero, H. 2013. Año 1939. Un museo paleontológico para Tarija. Diario El País (27 mayo 2013).

www.elpaisonline.com >sociales-2>item( 3 enero 2017).

\section{Enlaces consultados}

www.asur.org.bo $>$ museo $>$ museo www.bolivian.com/arqueologíal www.ilam.org $>$ index.php $>$ museo www.musef.org.bo www.museotablasmonte.org www.museo.umss.edu.bo www.wikipedia.com

Las imágenes presentadas pertenecen a la autora, salvo en los casos que se indica lo contrario. 